\title{
África, Brasil e as transformações no ENEM: a Lei $n^{\circ} 10.639 / 2003$
}

\author{
Alvaro de Oliveira Senra ${ }^{a}$ \\ Márcio de Araújo Moreira ${ }^{a}$ \\ Celiana Maria dos Santos ${ }^{b}$
}

\section{Resumo}

Este artigo tem como foco e busca analisar o impacto da Lei $\mathrm{n}^{\circ} 10.639 / 2003$ na formulação de questões do Exame Nacional do Ensino Médio (ENEM), no período compreendido entre os anos de 1998 e 2015. Desta forma, a pesquisa se situou na confluência de duas iniciativas de políticas públicas de grande relevância no Brasil contemporâneo: a primeira, de natureza generalista, dizendo respeito ao processo de avaliação da educação escolar e do acesso de estudantes ao ensino superior, e a segunda iniciativa voltada ao reconhecimento da contribuição dos negros africanos e de seus descendentes brasileiros à história e à cultura nacionais.

Palavras-chave:Educação escolar. Políticas públicas. Lei no 10.639/2003. Exame Nacional do Ensino Médio.

\section{Introdução}

O debate sobre políticas públicas que resgatem e ressignifiquem a história, a cultura e os direitos da população negra brasileira se constitui na arena de um dos maiores focos de tensão da vida política nacional na atualidade, encontrando convictos defensores e fortes opositores. As cotas raciais para o ingresso nas instituições públicas de ensino e no serviço público, o uso das mídias para a valorização da imagem e da identidade cultural dos cidadãos negros e a rediscussão sobre seu papel na construção histórica da nação são, hoje, temas da maior relevância, e de suas consequências dependerão os limites e as possibilidades da própria democracia no Brasil.

\footnotetext{
a Centro Federal de Educação Tecnológica Celso Suckow da Fonseca, Rio de Janeiro, Rio de Janeiro, Brasil.

b Instituto Federal de Educação, Ciência e Tecnologia da Bahia e Secretaria Estadual de Educação, Salvador, Bahia, Brasil.
} 
Por sua vez, o Exame Nacional do Ensino Médio (ENEM), aplicado desde 1998, com uma importante reforma de suas funções e objetivos em 2009, se constitui na atualidade em uma bem-sucedida experiência de avaliação do ensino e de ampliação de oportunidades para o acesso ao ensino superior. Da mesma forma que as políticas voltadas mais especificamente à população negra, e, contemporâneo ao seu tempo histórico, o ENEM, por suas proposições e pelo conteúdo de suas provas, têm sido objeto de debates envolvendo diversos setores da sociedade civil brasileira.

Este artigo objetiva, focaliza e busca analisar o impacto da Lei $\mathrm{n}^{\circ} 10.639 / 2003$, que "altera a Lei de Diretrizes e Bases da Educação Nacional, para incluir no currículo oficial da rede de ensino a obrigatoriedade do ensino da História e Cultura Afro-brasileira e da África" (BRASIL, s/d a, p. 127) na formulação de questões do ENEM, a partir da seleção do conteúdo utilizado pelas quatro áreas das Ciências Humanas: Geografia, História, Filosofia e Sociologia.

O recorte temático foi delimitado pelas avaliações aplicadas no ENEM e a forma como ocorreu a abordagem da Lei $\mathrm{n}^{\circ} 10.639$ (BRASIL, 2003a) nos itens do Exame, desde o seu início até o exame de 2015.

Buscou-se, com a pesquisa aqui desenvolvida, aferir a adequação aos conteúdos abordados nos itens do ENEM às transformações ocorridas na educação escolar posteriormente à promulgação da Lei no 10.639 (BRASIL, 2003a).

A base metodológica de conteúdos, que possibilitou descrições sistemáticas, qualitativas e quantitativas, dos itens do ENEM que abordaram o negro, nos possibilitou reinterpretar as mensagens e alcançar um entendimento de seus significados que vai além da leitura ordinária. A matéria da análise do nosso conteúdo foi constituída pelos temas ligados ao negro nas provas do ENEM e esses dados brutos foram processados para facilitar o trabalho de compreensão, interpretação e inferência a que aspira esse tipo de análise, servindo de suporte para captar seus sentidos simbólicos, que nem sempre se manifestam e também não têm um significado único. Por exemplo, a persistência de questões sobre escravidão justificou conteúdos históricos e geográficos como a colonização de exploração e a divisão do trabalho na colônia, mas deixou de considerar a existência de elementos de valorização dessa população, de suas culturas e de sua participação na formação do nosso povo (MOREIRA, 2015).

Para a execução da pesquisa foi necessária a análise de 16 anos de conteúdos do ENEM, entre 1998 e 2015, quando foi realizado o último Exame fornecedor de dados para a pesquisa que resultou neste artigo, possibilitando a delimitação e a contextualização do objeto de estudo. Sendo o período temporal relativamente 
grande, desejou-se levar em consideração as transformações que ocorreram na legislação e também considerar a evolução da importância assumida pelo ENEM ao longo de sua existência, sobretudo após 2009, quando passou a ser um instrumento de conclusão do Ensino Médio para estudantes com 18 ou mais anos de idade.

Um total de 1008 itens do ENEM foi abordado. A contagem dos elementos textuais encontrados no exame serviu para a organização e sistematização dos dados, e a fase analítica posterior permitiu apreender a visão social evidenciada a partir dos itens do material analisado.

Ao examinarmos as questões do ENEM, ponderamos que estas apresentam um conteúdo que carrega mais de 500 anos de história do nosso país, trazendo em si sentidos que não lhes são atribuídos somente pelo pesquisador, mas por toda a população; que veiculam interesses e visões de mundo historicamente construídas; e que, tradicionalmente, relacionaram a imagem do negro à escravidão e à subalternidade.

A pesquisa que resultou neste artigo abordou, portanto, a confluência de duas iniciativas de políticas públicas de grande relevância no Brasil contemporâneo: a primeira, de natureza generalista e dizendo respeito ao processo de avaliação da educação escolar e do acesso de estudantes ao ensino superior, e a segunda iniciativa voltada ao reconhecimento da contribuição dos africanos e de seus descendentes brasileiros à história, à sociedade e à cultura nacionais.

Por fim, a relevância da temática contida neste artigo se justifica pelo impacto da Lei $\mathrm{n}^{\circ} 10.639$ (BRASIL, 2003a) na educação brasileira, impacto que pode ser medido pela inovação curricular e de atitudes de autoridades, docentes e alunos e, também, pela resistência que provoca até hoje em amplos setores da vida política e da sociedade; se explicita, também, pela amplitude nacional da prova do ENEM, oferecida a todos os alunos que estão finalizando ou terminaram o ensino médio, ou que são adultos e desejam obter esse grau de conclusão, podendo, através da realização do Exame, ter acesso a instituições de ensino superior em todo o país e em Portugal, onde, atualmente, oito universidades aceitam seus resultados para o ingresso de alunos.

\section{A Lei $\mathrm{n}^{\circ} 10.639 / 2003$ e o ENEM}

A Lei ${ }^{\circ}$ 10.639(BRASIL, 2003a) contempla reivindicações de longa data do movimento negro no Brasil, articulado e atuante, de diversas formas, ao longo de todo o período republicano. Deve ser registrado que o advento da República não assegurou ganhos materiais ou simbólicos para a população negra, que continuou marginalizada em termos econômicos, políticos, sociais e culturais. 
Se, durante todo o século XX, negros se organizaram politicamente contra o racismo e por iguais oportunidades, a ênfase atual no reconhecimento da especificidade da identidade cultural de matriz africana e afro-brasileira se fortaleceu após a década de 1970. Coincidindo com a crise do Regime Militar (1964-1985), a rearticulação do Movimento Negro indicou uma série de ações de natureza simbólica, como o esvaziamento da tradicional comemoração de 13 de maio (abolição da escravidão) e valorização da data de 20 de novembro, possível dia da morte de Zumbi dos Palmares, como Dia Nacional de Consciência Negra. Além disso, o movimento negro passou a reivindicar seus direitos no campo educacional. Conforme Borges (1982), foram propostas a revisão dos conteúdos preconceituosos dos livros didáticos; a capacitação dos docentes para desenvolver uma pedagogia multiétnica; a reconstrução da imagem e do papel do negro na história do Brasil e, também, levantou-se a bandeira da inclusão do ensino da história da África nos currículos escolares, bem antes mesmo da homologação da nova Lei de Diretrizes e Bases (LDB) de 1996 (SAVIANI, 1999), constituindo a semente embrionária da Lei $\mathrm{n}^{\circ} 10.639$ (BRASIL, 2003a), que alteraria posteriormente essa mesma LDB.

Pode-se registrar a relevância dada a reivindicações voltadas para a educação escolar, na medida em que se percebe, no interior das escolas e no material didático por elas adotado, a persistência de concepções e práticas que reforçam a subalternidade e a invisibilidade cultural dos negros. Para Amauri Mendes Pereira, a escola, em sentido inverso, pode ser um espaço privilegiado de construção da consciência acerca da cultura negra:

A população negra não sucumbiu nem física, nem culturalmente ao racismo; a ponto de estar hoje em aberto, como um dilema, a reconceituação da identidade nacional brasileira, numa espetacular virada sobre as projeções etnocêntricas das elites no início do século. Que mecanismos estarão sendo criados - surda e subterraneamente - em comunidades escolares, em face desses e outros tantos desafios para uma educação democrática, construtora dos valores de equidade, justiça e solidariedade? E no íntimo de cada criança, na medida que vão crescendo e se deparando com um mundo (físico e de valores) em acelerada transformação? (PEREIRA, 2005, p. 45).

A materialização das reivindicações acima citadas reforçou a identidade negra, visível não somente na estética ou nas artes, contribuindo, também, para a positivação da condição negra, da história da África e da contribuição do negro para a constituição da sociedade brasileira. A partir de 1985, a pressão dos movimentos 
sociais e uma maior abertura dos governos democráticos possibilitaram a criação de instrumentos legais de combate ao racismo e de valorização da população negra.

Ao mesmo tempo, desde a redemocratização do país, em 1985, a educação escolar no Brasil tem passado por grandes transformações, associadas estas à expansão das políticas públicas e ao aumento das demandas sociais por educação formal. Essas transformações tiveram como grandes marcos legais a Constituição democrática de 1988, a LDB de 1996 e uma série de iniciativas que, a partir da década de 1990 e do governo de Fernando Henrique Cardoso (1994-2002) permitiram a criação de mecanismos inéditos de centralização decisória e de recursos, como Fundo de Desenvolvimento do Ensino Fundamental e Valorização do Magistério (Fundef), depois estendido ao conjunto do ensino básico, os Parâmetros Curriculares Nacionais (PCNs) e o "Provão" para todos os níveis de ensino. Os governos de Lula da Silva (2002-2010) e Dilma Rousseff (2010-2016) mantiveram e ampliaram esses mecanismos; entre eles se encontra o ENEM.

O Governo Federal criou o ENEM em 1998 como uma prova de caráter nacional com o objetivo de ser instrumento de aferição da educação secundária e com o intuito futuro de democratizar o acesso ao ensino superior. No seu primeiro ano de aplicação, 66 mil estudantes se inscreveram no Exame; em 2015, consolidado como parâmetro para o ingresso em diversas instituições de ensino superior, esse número foi próximo a nove milhões de inscritos.

A evidente relevância do ENEM não o isenta de críticas e preocupações; em si, ele não elimina problemas crônicos da educação brasileira, como as condições desiguais de competição apresentadas entre alunos de escolas privadas e públicasno caso destas, com a exceção das escolas de ponta, em geral as da rede federal-, assim como os desequilíbrios regionais, sociais e raciais, que tanto influenciam na educação anterior dos alunos inscritos. Outro problema, o da mobilidade acadêmica proporcionada pelo ENEM, é problematizado por Aparecida da Silva Xavier Barros:

A mobilidade acadêmica é uma das bandeiras do Enem. Essa "mobilidade" está no fato do estudante poder escolher até duas opções de curso entre as vagas ofertadas pelas instituições participantes do Sisu. Porém, o que é mostrado como uma grande "revolução" no ensino superior brasileiro, na prática, revela uma situação ainda mais agressiva e desigual. Os melhores alunos de todos os estados irão para as melhores universidades do país, restando para os demais, cursos distantes de casa ou fora de sua preferência. Muitos deles, mesmo aprovados, nem irão para a universidade. [...] O acesso à graduação, nesse caso, está relacionado ao número de pontos obtidos no Enem e à quantidade de 
vagas que o curso da preferência do estudante possui. Ou seja, não muito diferente do que sempre foi visto no vestibular. Em outras palavras, a lógica do mercado presente nesse tipo de prova permanece na política atual do governo, pois os alunos que não tiveram um ensino voltado para esse tipo de seleção continuarão em condições menos favoráveis para ingressar no ensino superior (BARROS, 2014, p. 1082-1083).

O ano de 2009 foi um marco na relevância nacional do ENEM, pois o Ministério da Educação apresentou uma proposta para que o Exame passasse a ser instrumento de avaliação e seleção unificada para o ingresso de estudantes nas universidades públicas federais e de conclusão do Ensino Médio para os maiores de 18 anos em qualquer lugar do país.

Com a reformulação, propôs-se democratizar as oportunidades de acesso às vagas nas universidades federais, possibilitar a mobilidade acadêmica e induzir a reestruturação dos currículos do ensino médio, pois, além de analisar a qualidade desse ensino, o ENEM pôde também criar diretrizes a serem seguidas em disciplinas que não possuíam planos nacionais curriculares concretizados, assim como pôde garantir a determinação do cumprimento de leis que privilegiassem políticas públicas afirmativas, como as propostas pela Lei $n^{\circ} 10.639$ (BRASIL, 2003a). As provas do Exame puderam incentivar a abordagem desses temas na grade curricular das instituições públicas e particulares de ensino.

Nos seus primeiros anos a avaliação realizada pelo ENEM foi produzida pela Fundação Cesgranrio. Em 2010, o Instituto Nacional de Estudos e Pesquisas Educacionais Anísio Teixeira (INEP), órgão público responsável pela organização do ENEM, convidou professores de ensino médio, através de uma chamada pública, para participar de oficinas de elaboração de itens, aproximando mais a discussão das novas matrizes de referências para as salas de aulas de todo o país. Esta chamada pública inseriu-se dentro de um processo mais amplo de estruturação para que o INEP assumisse diretamente a responsabilidade pela formulação dos seus instrumentos de avaliação, constituindo, para tal, um sistema de elaboração da revisão de itens. Outro objetivo dessa nova metodologia era também, aumentar a participação da comunidade acadêmica de todo o Brasil nos processos de avaliação educacional desenvolvidos pelo INEP.

A partir de 2011, professores que haviam sido selecionados pela chamada pública do INEP realizada no ano anterior, bem como professores universitários cujas instituições aderiram ao ENEM, participaram dos processos de elaboração de itens para o Banco Nacional de Itens (BNI) promovidos pelo INEP através de oficinas descentralizadas. Alguns desses professores foram convidados a integrar a Diretoria de Avaliação da 
Educação Básica/Coordenadoria-Geral de Instrumentos e Medidas (DAEB/CGIM) e se associaram à leitura fina de itens do BNI, visando ao aprimoramento da avaliação.

Acreditamos que essas reformulações permitiram a convergência do ENEM com outro grande movimento observado nas políticas públicas no Brasil, já que, na prova do ENEM referente ao ano letivo de 2011, os primeiros resultados começaram a aparecer, com questões que valorizaram a cultura e a participação dos negros na História da sociedade brasileira.

O outro movimento acima citado, de forma correlata à implantação do ENEM e a outras mudanças legais ocorridas na educação escolar nos anos que se seguiram à redemocratização, está relacionado a políticas de outra natureza, não generalista, mas dirigidas a setores específicos da população, reivindicadas por movimentos da sociedade civil e implementadas pelo Estado. Essas políticas afirmativas, consolidadas nas duas últimas décadas, tiveram como foco principal a população negra brasileira, historicamente vítima do racismo e da desigualdade social.

Deve-se observar que a discussão sobre as políticas públicas com o objetivo específico de beneficiar a população negra (e também indígena) foi inibida pela crença, bastante enraizada, de que no Brasil existiria uma "democracia racial" e de que os casos de preconceito e de discriminação tinham origem nas desigualdades sociais. Tomemos, a título de exemplo, a primeira Lei de Diretrizes e Bases [Lei no 4.024/1961(BRASIL, 1961)]. Embora no seu processo de discussão a desigualdade racial preocupasse não se tornou objeto central da atenção dos educadores envolvidos na sua feitura. Nas palavras de Lucimar Rosa Dias,

[...] como discurso, a inclusão racial fez parte das preocupações dos educadores e foi uma dimensão considerada no universo da discussão da LDB de 1961. Contudo, observamos que essa dimensão ocupou papel secundário, servindo mais como recurso discursivo. Ou seja, ao defender um ensino para todos, não ignoravam esses educadores que, além da classe, a dimensão raça era fator de diferenciação no processo de escolaridade. Mas não se falava explicitamente na época se a população negra era a destinatária principal da escola pública e gratuita (DIAS, 2005, p. 52).

A autora, no entanto, ressalta que isso não significa ausência da temática racial entre os educadores, indicando o artigo $1^{\circ}$, alínea g do Título I da Lei n⿳⺈.024, no qual se estabelece "a condenação a qualquer tratamento desigual por motivo de convicção filosófica, política ou religiosa, bem como a quaisquer preconceitos de classe ou de raça" (DIAS, 2005, p. 52). 
Deve-se notar, no entanto, que a ideia de "democracia racial" (FREYRE, 2006) teve e continua a ter, grande influência nas práticas docentes, constituindo-se em um obstáculo para a consolidação da Lei no 10.639 (BRASIL, 2003a) e para o persistente silêncio, nas salas de aula, para os problemas decorrentes das diferenças e dos preconceitos raciais (COSTA, 2013, p. 121-124).

Apesar dessa crença, a ampliação da luta antirracista ainda sob o Regime Militar, o crescente descrédito na ideia de "democracia racial" e, após 1985, a maior mobilização social e a assertividade do Estado - na forma de criação de canais de participação dos movimentos sociais e de legislação específica ampliaram o rol de instrumentos para a luta contra o racismo e a discriminação racial. Conforme Guimarães,

os anos seguintes, que se estendem de 1985 a 1995, são de construção de uma nova institucionalidade política; de formação da Nova República, como se chamou na época. Os ativistas negros serão chamados a ocupar cargos nos recém-criados Conselhos e Secretarias da Comunidade Negra, no âmbito dos governos estaduais, e na Fundação Palmares, criada em 1988, no âmbito do Ministério da Cultura. De grande efeito simbólico foi o tombamento, como patrimônio cultural brasileiro, da Serra da Barriga, local onde existiu no século XVII o Quilombo dos Palmares. O governo federal começava, assim, ao menos no plano simbólico, a incorporar as demandas do Movimento Negro (GUIMARÃES, 2002, p. 161).

Tome-se como exemplo o ano de 1989, quando o presidente José Sarney (1985-1990) homologou a Lei no 7.716 (BRASIL, 1989). Nela consta a punição aos crimes resultantes de discriminação ou preconceito de raça, cor, etnia, religião ou procedência nacional.

As transformações observadas na abordagem da questão racial, no entanto, no Brasil após a década de 1980 não se limitaram à ampliação dos canais de diálogo entre Estado e sociedade ou à elaboração de um conjunto de leis. Novas concepções redefiniram a importância da diversidade no interior da sociedade brasileira, superando a ênfase na mestiçagem cultural uniformizadora, característica das décadas intermediárias do século XX (ORTIZ, 2015, p.158-159).

Essas novas concepções e perspectivas de abordagem da sociedade se enraizaram no âmbito acadêmico, atingiram amplos setores da vida cultural e se ampliam até o campo educacional, alcançando, a partir do final da década de 1980 e ao longo 
da década seguinte, a pauta das políticas voltadas para a formação de professores (CANEN; XAVIER, 2005, p. 339).

$\mathrm{Na}$ atualidade, perspectivas e preocupações com o respeito e a preservação da diversidade cultural, incluindo-se os indígenas e as populações tradicionais, como os quilombolas, podem ser observadas nos espaços de debate e nos diferentes níveis do poder público, tendo sido incluídas no próprio Plano Nacional de Educação (2011-2020), embora sua implantação seja dada de forma contraditória e lenta (BATISTA; SILVA JUNIOR; CANEN, 2013, p. 258-9).

Essas perspectivas e preocupações resultam na incorporação de identidades e o reconhecimento do direito à diversidade, as quais passam a ser fundamentais na luta das populações negras pelos seus direitos. A obrigatoriedade do ensino de História e da cultura africana e afro-brasileira nos currículos da educação básica tem, nesse sentido, intensas repercussões pedagógicas. A sua relevância não se restringe à população negra: ao contrário, diz respeito a todos os brasileiros, uma vez que esses devem educar-se enquanto cidadãos atuantes no seio de uma sociedade democrática, multicultural e pluriétnica.

De qualquer forma, ao longo das décadas de 1990 e 2000, foram-se fortalecendo as iniciativas que iam além da legislação punitiva aos atos de racismo e discriminação, indicando a valorização cultural e histórica do negro como forma de reparação, além da instituição de políticas de cotas raciais para ingresso em instituições públicas de ensino. É dentro desse cenário que ressaltamos a importância de leis que contemplam políticas afirmativas como a Lei nº10.639 (BRASIL, 2003a), além de outras providências de valorização do papel histórico dos negros no Brasil, entre os quais a inclusão do dia 20 de novembro como "Dia Nacional da Consciência Negra".

Ao questionar a tradicional centralidade atribuída à História e à cultura de origem europeia nos conteúdos da educação escolar, a Lei 10.639 (BRASIL, 2003a) critica um dos elementos de reprodução de uma hierarquia racial que sempre girou em torno da branquitude como fundamento de poder, riqueza e status. Agindo em sentido contrário, cria perspectivas para o enraizamento de concepções de mundo que possibilitam o reconhecimento igualitário das diversas matrizes formativas da sociedade brasileira, destacando, em especial, a contribuição da África, de seus povos e de seus descendentes brasileiros. A Lei, neste sentido, pode ser considerada um marco de grande relevância histórica, pois atinge um dos principais pilares das seculares desigualdades da sociedade brasileira: a educação. 
A entrada em vigor da Lei $\mathrm{n}^{\circ} 10.639$ (BRASIL, 2003a) abriu o caminho para a inclusão de conteúdos nela baseados para a construção de itens incluídos nas provas do ENEM. Para a aferição se esses itens foram ou não materializados em questões nas provas do período temporal abrangido pela pesquisa, estabelecemos uma classificação das formas de abordagens do negro nas questões do ENEM. Essa classificação tem uma natureza didática e explicativa, não se propondo a se transformar numa categoria analítica rígida.

A primeira forma, que denominamos de tradicional, contextualiza a participação do negro na História e na sociedade brasileira, em função de sua condição de subalternidade, mesmo que resistente ou rebelde a esta condição; nessa visão, a presença do negro, de modo geral, está relacionada à escravidão ou às classes e segmentos sociais em condição de inferioridade na ordem social pós-escravista. Ressaltamos que tradicional, no caso aplicado, não significa uma visão preconceituosa, conservadora ou racista, mas apegada a concepções que sugerem subalternidade ou reatividade a um contexto opressivo.

Pode-se exemplificar essa visão tradicional na Figura 1 que constou no ENEM de 2007.

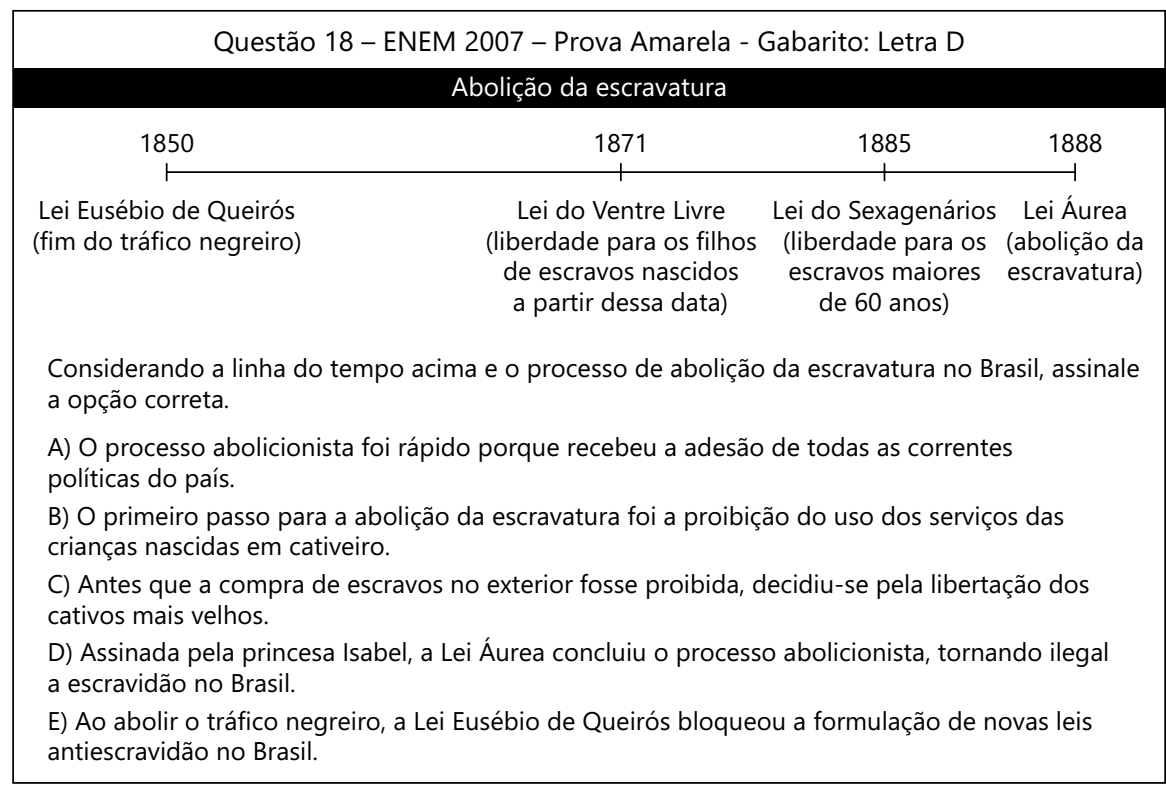

Fonte: http://download.inep.gov.br/educacao_basica/enem/provas/2007/2007_amarela.pdf. Acesso em:26 maio 2016.

Figura 1. Questão 18 - ENEM 2007 - Prova Amarela - Gabarito: Letra D. 
A outra classificação, que denominamos de renovadora, se relaciona às indicações contidas na Lei ${ }^{\circ} 10.639$ (BRASIL, 2003a). Um exemplo de abordagem renovadorapode ser encontrado na questão 32 do Exame aplicado em 2011 (Figura 2).

Outros exemplos da utilização de uma visão renovadorado negro estão nas questões 9, 10 e 32 (respectivamente, Figuras 3, 4 e 5), aplicadas no ENEM de 2012, 2014 e 2015.

Mais uma vez, identificamos a relevância de se incluir questões baseadas na Lei $\mathrm{n}^{\circ} 10.639$ (BRASIL, 2003a), pois, pela importância social e educacional que o ENEM possui na atualidade, os itens de suas provas acabam por criar tendências que colaboram para a adequação da grade curricular das disciplinas ministradas no ensino básico e a reformulação de livros didáticos, que passam a valorizar a contribuição do negro.

A partir da catalogação das questões do ENEM, foi elaborado o Quadro, abarcando em todo o período abordado a partir da classificação estabelecida: aquelas (renovadoras) que contemplaram a Lei $\mathrm{n}^{\circ} 10.639$ e aquelas que abordaram o negro de forma tradicional.

Questão 32 - ENEM 2011 - Prova Amarela - Gabarito: Letra E

A Lei 10.639, de 9 de janeiro de 2003, inclui no currículo dos estabelecimentos de ensino fundamental e médio, oficiais e particulares, a obrigatoriedade do ensino sobre História e Cultura Afro-Brasileira e determina que o conteúdo programático incluirá o estudo da História da África e dos africanos, a luta dos negros no Brasil, a cultura negra brasileira e o negro na formação da sociedade nacional, resgatando a contribuição do povo negro nas áreas social, econômica e política pertinentes à História do Brasil, além de instituir, no calendário escolar, o dia 20 de novembro como data comemorativa do "Dia da Consciência Negra".

Disponível em: http://www.planalto.gov.br. Acessado em: 26 de maio de 2016 (adaptado).

A referida lei representa um avanço não só para a educação nacional, mas também para a sociedade brasileira, porque

A) legitima o ensino das ciências humanas nas escolas.

B) divulga conhecimentos para a população afro-brasileira.

C) reforça a concepção etnocêntrica sobre a África e sua cultura.

D) garante aos afrodescendentes a igualdade no acesso à educação.

E) impulsiona o reconhecimento da pluralidade étnico-racial do país.

Fonte:http://download.inep.gov.br/educacao_basica/enem/provas/2011/02_AMARELO_GAB.pdf. Acesso em:26 maio 2016.

Figura 2. Questão 32 - ENEM 2011 - Prova Amarela - Gabarito: Letra E. 


\section{Questão 9 - ENEM 2012 - Prova Amarela - Gabarito: Letra A}

Torna-se claro que quem descobriu a África no Brasil, muito antes dos europeus, foram os próprios africanos trazidos como escravos. E esta descoberta não se restringia apenas ao reino linguístico, estendia-se também a outras áreas culturais, inclusive à da religião. Há razões para pensar que os africanos, quando misturados e transportados ao Brasil, não demoraram em perceber a existência entre si de elos culturais mais profundos.

SLENES, R. Malungu, ngoma vem! África coberta e descoberta do Brasil. Revista USP, n. 12, dez./jan./fev. 1991-92 (adaptado).

Com base no texto, ao favorecer o contato de indivíduos de diferentes partes da África, a experiência da escravidão no Brasil tornou possível a

A) formação de uma identidade cultural afro-brasileira.

B) superação de aspectos culturais africanos por antigas tradições europeias.

C) reprodução de conflitos entre grupos étnicos africanos.

D) manutenção das características culturais específicas de cada etnia.

E) resistência à incorporação de elementos culturais indígenas.

Fonte: http://download.inep.gov.br/educacao_basica/enem/provas/2012/caderno_enem2012_ sab_amarelo.pdf. Acesso em:26 maio 2016.

Figura 3. Questão 9 - ENEM 2012 - Prova Amarela - Gabarito: Letra A.

\section{Questão 10 - ENEM 2014 - Prova Amarela - Gabarito: Letra A}

\section{Estatuto da Frente Negra Brasileira (FNB)}

Art. $1 .^{\circ}$ - Fica fundada nesta cidade de São Paulo, para se irradiar por todo o Brasil, a Frente Negra Brasileira, união política e social da Gente Negra Nacional, para a afirmação dos direitos históricos da mesma, em virtude da sua atividade material e moral no passado e para reivindicação de seus direitos sociais e políticos, atuais, na Comunhão Brasileira.

Diário Oficial do Estado de São Paulo. 4 nov. 1931.

Quando foi fechada pela ditadura do Estado Novo, em 1937, a FNB caracterizava-se como uma organização

A) política, engajada na luta por direitos sociais para a população negra no Brasil.

B) beneficente, dedicada ao auxílio dos negros pobres brasileiros depois da abolição.

C) paramilitar, voltada para o alistamento de negros na luta contra as oligarquias regionais.

D) democrático-liberal, envolvida na Revolução Constitucionalista conduzida a partir de São Paulo.

E) internacionalista, ligada à exaltação da identidade das populações africanas em situação

de diáspora.

Fonte: http://download.inep.gov.br/educacao_basica/enem/provas/2014/CAD_ENEM_2014_ DIA_1_02_AMARELO.pdf. Acesso em:26 maio 2016.

Figura 4. Questão 10 - ENEM 2014 - Prova Amarela - Gabarito: Letra A. 


\section{Questão 32 - ENEM 2015 - Prova Amarela - Gabarito: Letra E}

\section{Voz do sangue}

Palpitam-me

os sons do batuque

e os ritmos melancólicos do blue.

Ó negro esfarrapado

Do Harlem

ó dançarino de Chicago

ó negro servidor do South

Ó negro da África

negros de todo o mundo

Eu junto

ao vosso magnifico canto

a minha pobre voz

os meus humildes ritmos.

Eu vos acompanho

pelas emaranhadas Áfricas

do nosso Rumo.

Eu vos sinto

negros de todo o mundo

eu vivo a nossa história

meus irmãos.

Nesse poema, o líder angolano Agostinho Neto, na década de 40, evoca o pan-africanismo com o objetivo de

A) incitar a luta por políticas de ações afirmativas na América e na África.

B) reconhecer as desigualdades sociais entre os negros de Angola e dos Estados Unidos.

C) descrever o quadro de pobreza após os processos de independência no continente africano.

D) solicitar o engajamento dos negros estadunidenses na luta armada pela independência em Angola.

E) conclamar as populações negras de diferentes países a apoiar as lutas por igualdade e independência.

Fonte: http://download.inep.gov.br/educacao_basica/enem/provas/2015/CAD_ENEM\%20 2015_DIA\%201_02_AMARELO.pdf. Acesso em:26 maio 2016.

Figura 5. Questão 32 - ENEM 2015 - Prova Amarela - Gabarito: Letra E.

Verificamos no Quadro que, nos anos abordados pela pesquisa, foram aplicados 19 Exames (em 2010: o primeiro Exame foi anulado, mas consideramos suas questões). A partir da análise de todas as questões no período entre 1998 e 2008, quando a prova era única com 64 questões de todas as disciplinas, e da análise das questões das provas de Ciências Humanas entre 2009 e 2015, período em 
Quadro. Questões renovadoras e tradicionais contemplando o negro no ENEM (1998-2015).

\begin{tabular}{|c|c|c|}
\hline Ano & $\begin{array}{c}\text { Questões com visão renovadora } \\
\text { sobre o negro contemplando } \\
\text { a Lei } \mathbf{~ n}^{\mathbf{1 0}} \mathbf{1 0 3 9}\end{array}$ & $\begin{array}{c}\text { Questões com visão tradicional } \\
\text { sobre o negro no Brasil }\end{array}$ \\
\hline 1998 & 0 & 1 \\
1999 & 0 & 0 \\
2000 & 0 & 0 \\
2001 & 0 & 0 \\
2002 & 0 & 0 \\
2003 & 0 & 1 \\
2004 & 1 & 0 \\
2005 & 0 & 2 \\
2006 & 0 & 1 \\
2007 & 0 & 3 \\
2008 & 0 & 2 \\
2009 & 0 & 1 \\
$2010(1)$ & 0 & 4 \\
$2010(2)$ & 0 & 4 \\
2011 & 1 & 1 \\
2012 & 2 & 1 \\
2013 & 4 & 2 \\
2014 & 3 & 0 \\
2015 & 3 & 1 \\
TOTAL & 0 & 24 \\
\hline
\end{tabular}

Fonte: http://portal.inep.gov.br/web/enem/edicoes-anteriores/provas-e-gabaritos. Acesso em: 28 maio 2016.

que ocorre a separação da prova em áreas de conhecimento, foi observado que itens com visões renovadorasque ressaltam a cultura e a contribuição do negro na formação da sociedade brasileira foram incluídos na prova em 14 vezes.

Já itens tradicionais, que mantêm a visão do negro retratada em programas, aulas e livros didáticos durante décadas foram contemplados em 24 oportunidades. Um fato observado que chamou a atenção é que até 2003, quando a Lei n ${ }^{\circ} 10.639$ (BRASIL, 2003a) foi promulgada, temas sobre a população negra no Brasil foram praticamente ignorados.

Antes de 2003, a única referência ao negro foi no primeiro ano de aplicação da prova, num item tradicional, sobre a escravidão. Depois disso, foram quatro Exames 


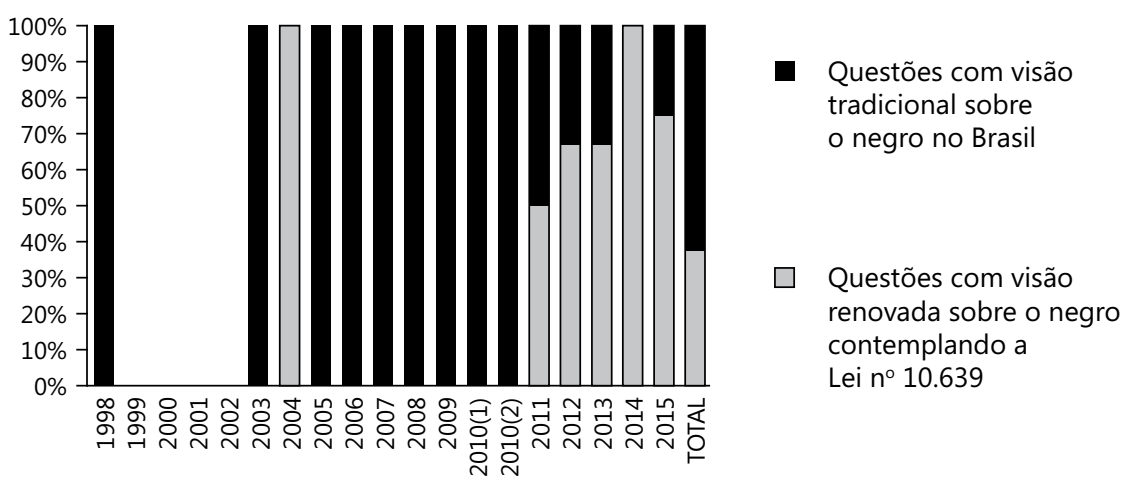

Fonte : http://portal.inep.gov.br/web/enem/edicoes-anteriores/provas-e-gabaritos. Acesso em: 28 maio 2016.

Gráfico 1. Abordagem do Negro no ENEM de 1998 a 2015.

de silêncio em relação a qualquer aspecto sobre a população negra. A primeira questão escrita sob bases renovadoras foi apresentada em 2004, ano seguinte à entrada em vigor da Lei e seis anos após o início do ENEM. Após esse ano, uma ausência dequestões renovadoras ocorreu por mais sete anos, até 2011, sendo o negro representado nos itens apenas sob o prisma da escravidão ou da opressão, mesmo com a reformulação da LDB e com a criação da legislação citada. Infere-se, assim, que a Lei $n^{\circ} 10.639$ (BRASIL, 2003a), durante um período significativo, foi desconsiderada e também mal interpretada, pois abordar o negro como escravo ou oprimido, embora reconheça seu papel na construção deste país e o seu sofrimento, o deixa na condição de subordinado, não cumprindo as determinações da legislação.

O Gráfico 2 permite uma visualização da dificuldade em aplicar a Lei ${ }^{\circ} 10.639$, mostrando que a lei, em si, até então não fora eficaz para modificar a tendência explicitada nas questões do ENEM.

Observa-se no Gráfico 2 que, após a promulgação da Lei no 10.639 até o último ano de aplicação do "Velho ENEM", a cultura negra brasileira e a abordagem histórica sobre a África tiveram uma presença insignificante na avaliação sobre o ensino médio nacional. Parecia que se delineava o caminho de mais uma lei que, na linguagem popular, "não pega" no Brasil.

Somente a partir de 2011 quando foi formada uma nova DAEB/CGIM, que colabora pedagogicamente com a instituição, é que o INEP passou a ter sucesso contínuo no objetivo de elencar conteúdos que se aproximavam das proposições da Lei $\mathrm{n}^{\circ}$ 10.639; desde aquele ano, questões sobre os negros ocupam espaço de forma mais significativa destacando o reconhecimento de sua importância histórica e a 
revalorização de sua herança cultural. Esses conteúdos abordados nas habilidades e competências voltaram a integrar os itens do exame para não mais sair, desde então.

O Gráfico 3 permite as mudanças ocorridas desde 2011 nas questões que abordam o negro no ENEM.

Nota-se que houve um crescimento de $10 \%$ para $72 \%$ das questões com abordagem renovadora, quando comparamos esse período dentro da escala de tempo do Novo ENEM (2011-2015) com o período anterior, entre a promulgação da Lei $\mathrm{n}^{\circ} 10.639$ (BRASIL, 2003a) e o último ano do "Velho ENEM" (2003-2008). Atualmente, temas referentes ao estudo da História da África e dos africanos,
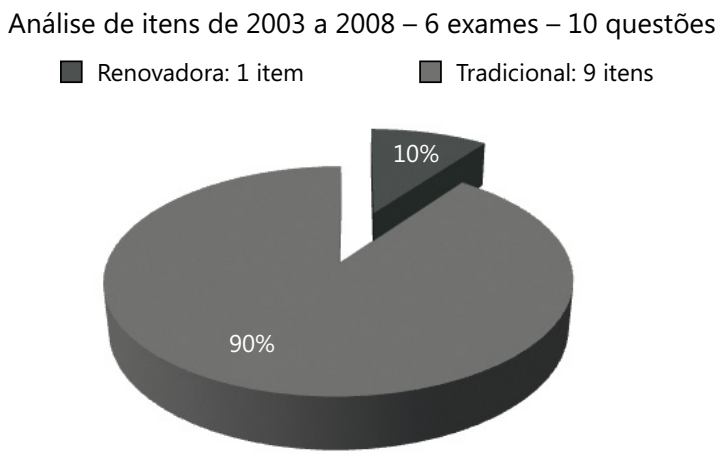

Fonte: http://portal.inep.gov.br/web/enem/edicoes-anteriores/provas-e-gabaritos. Acesso em: 28 maio 2016.

Gráfico 2. Formas de Abordagem Geral do Negro no ENEM de 2003 a 2008.
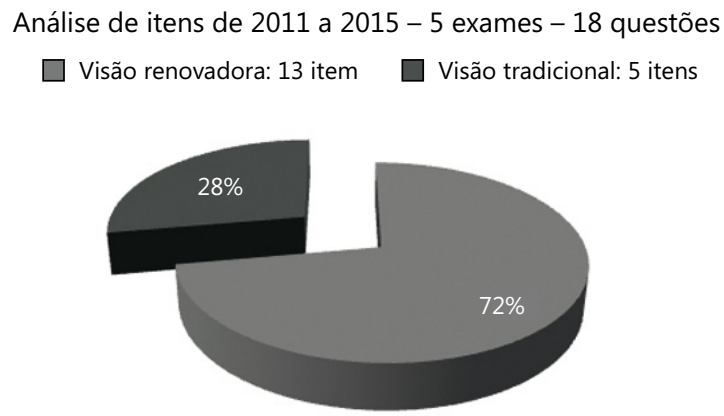

Fonte : http://portal.inep.gov.br/web/enem/edicoes-anteriores/provas-e-gabaritos. Acesso em: 28 maio 2016.

Gráfico 3. Forma de Abordagem Geral do Negro no ENEM de 2011 a 2015. 
à luta dos negros no Brasil, à cultura negra brasileira e ao papel do negro na formação da sociedade nacional, resgatando suas contribuições e valorizando sua identidade, fazem parte do conteúdo das provas do ENEM.

Até o momento em que se encerrou a pesquisa aqui realizada, as abordagens que promovem a valorização da população negra nos itens do ENEM, de acordo com os ditames das Lei no 10.639 (BRASIL, 2003a), estavam em condição minoritária: foram 14 itens com visão renovadora contra 24 de uma visão tradicional; porém, esse conjunto em termos percentuais vem se transformando nos últimos anos, superando os 50\% desde 2011 e dando um novo caráter à avaliação, pois ano a ano ganham mais espaço na prova. Temos aí um indicativo do crescente enraizamento da Lei $\mathrm{n}^{\circ} 10.639$ (BRASIL, 2003a) entre os agentes que elaboram as questões, com desdobramentos que tendem a atingir o conjunto do ensino médio (Gráfico 4).

Consolidada a tendência verificada nos ENEM, a partir da primeira metade da década de 2010, pode-se afirmar que a educação brasileira dispõe de um instrumento de avaliação de relevância fundamental, com capacidade de difundir entre a rede escolar e o conjunto da sociedade concepções que reconhecem e valorizam a contribuição dos africanos e de seus descendentes brasileiros, corrigindo toda uma trajetória de desigualdade e injustiça. Recorremos, novamente, a Dias:

A busca pela questão de raça nas leis educacionais foi uma tentativa de demonstrar que elas refletem a tensão presente na sociedade. De um lado, políticas que pretendem a permanência do racismo estrutural, revelado ora pela invisibilidade da raça, ora pelo mito da democracia. De outro, a luta pelo rompimento desses mecanismos.

\section{Análise de itens de 1998 a 2015 - 19 exames - 38 questões \\ Visão renovadora: 14 item $\square$ Visão tradicional: 24 itens}

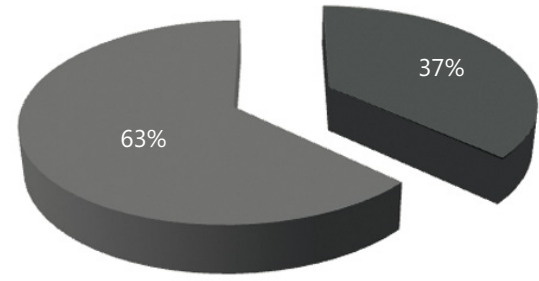

Fonte: http://portal.inep.gov.br/web/enem/edicoes-anteriores/provas-e-gabaritos.

Acesso em: 28 maio 2016.

Gráfico 4. Análise de itens de 1998 a 2015 - 19 exames - 38 questões. 
[...] parece-me que, para resolver essas questões, é preciso dar dois passos sempre. O primeiro é a lei; o segundo, o estabelecimento de políticas públicas que a efetivem (DIAS, 2005, p. 59-60).

A adoção das diretrizes da Lei ${ }^{\circ}$ 10.639(BRASIL, 2003a), nas questões de um Exame nacional unificado da dimensão do ENEM, constitui um importante instrumento de política educacional, na medida em que sinaliza concretamente para o ensino fundamental e médio orientações curriculares expressas de modo claro, com impacto sobre os conteúdos e as práticas docentes.

\section{Considerações finais}

Ao longo desse artigo, procuramos discorrer sobre a relevância do ENEM e sobre a possibilidade deste Exame impactar na difusão dos conteúdos previstos pela Lei ${ }^{\circ} 10.639$ (BRASIL, 2003a).

A nova legislação específica não deve ser tratada apenas como atendimento a uma demanda específica do movimento negro, pois ela altera a LDB e, portanto, representa modificações na normatividade da Educação nacional. Essa alteração não se resume a ser mais um mecanismo para combater o racismo e a intolerância no ambiente escolar, mas visa, também a formar futuros cidadãos com uma consciência de que a sociedade brasileira é multiétnica, culturalmente diversa e que essa diversidade não pode ser abordada sob o prisma de uma hierarquia que privilegia a matriz europeia, como sempre ocorreu. Devemos ressaltar que as consequências da Lei são importantes tanto para as escolas públicas de bairros populares, onde há grande presença de alunos negros, como também em instituições particulares de elite em todo o país, nos seus diversos segmentos.

O ENEM deve ser compreendido em sua configuração política, que potencializa estratégias e proporciona debates que podem ser utilizados para a superação de preconceitos e a valorização de contribuições políticas e culturais de segmentos até agora pouco reconhecidos da sociedade brasileira.

A identificação dos itens de Ciências Humanas do ENEM entre os anos de 1998 e 2015 permitiu perceber que a abordagem renovadora do negro, nos moldes pregados pela Lei ${ }^{\circ} 10.639$ (BRASIL, 2003a), avançou e conquistou um espaço mais representativo no Exame a partir de 2011. Foi aferido que os itens alicerçados por esta abordagem desfrutaram de uma participação na prova bem acima de sua média dos anos anteriores, sobretudo em temas transversais ligados à sociologia, regulamentada como obrigatória no Ensino Médio em 2009. 
No decorrer do trabalho, algumas características interessantes da dinâmica do Exame foram percebidas, tais como a grande relevância de temas sobre escravidão após a homologação da legislação que trata da obrigatoriedade do ensino de África e da cultura negra no Brasil. As questões sobre o negro e a África foram praticamente ignoradas nos anos iniciais do exame, e após a promulgação da lei, seus pressupostos foram confundidos com a abordagem das mazelas da escravidão e do período posterior à Abolição. A história e a consistente participação da sociologia com questões que discutiam elementos previstos na Lei ${ }^{\circ} 10.639$, a partir de 2011, são tão notáveis quanto a ausência de temas ligados à Geografia e à Filosofia, disciplinas que integram o quadro das ciências humanas.

A análise do conteúdo das questões permitiu chegar à conclusão de que as exigências da Lei $n^{\circ} 10.639$ (BRASIL, 2003a) estão sendo gradativamente colhidas e uma nova maneira de enxergar o papel no negro na nossa sociedade, no passado e no presente está em andamento, valorizando e enraizando, no ensino escolar, a diversidade cultural constitutiva da sociedade brasileira, contribuindo para relações mais igualitárias e democráticas. Ressaltam-se, aqui, os desdobramentos da Lei para a formação docente, na medida em que as graduações na área de Humanas, e as licenciaturas, em particular, foram obrigadas a introduzir disciplinas sobre a História da África e a Cultura africana e negra brasileira.

Pode-se ainda afirmar que a influência da abordagem baseada na Lei ${ }^{\circ} 10.639$ (BRASIL, 2003a) se ampliou após a criação do Novo ENEM, em 2009, quando efetivamente a prova, além de seu papel avaliador do ensino médio, passou a servir como parâmetro de ingresso em inúmeras instituições por todo país, e, em consequência, forjou parâmetros para a elaboração de currículos escolares. Isso quer dizer que a prova avalia a educação, mas também é avaliada por ela, na figura de escolas e docentes que se apropriam de seus conteúdos para elaborar seus planejamentos. Daí a grande importância do novo tratamento que é dispensado pelo INEP ao negro a partir das políticas afirmativas.

Desse modo, o ENEM se consolida como uma via que permite que a ressignificação do papel do negro na história e na sociedade brasileira chegue à sala de aula $\mathrm{e}$ aos manuais, constituindo um instrumento para o trabalho docente no ensino básico, pois o Exame tem a possibilidade de nortear ações pedagógicas na escola.

O cenário educacional estudado a partir dos itens do ENEM se demonstrou ao longo do tempo de forma favorável às novas abordagens sobre o negro brasileiro e à História da África, contudo, isso ocorre somente nos exames mais recentes, e mesmo assim, há um longo caminho a ser percorrido por todos os atores envolvidos nesse processo, inclusive no que diz respeito ao material didático 
usado nas escolas. Considera-se que pela importância absorvida pelo ENEM em todos esses anos de aplicação, e pelo caminho a ser seguido pela educação que avalia, seria interessante o INEP publicar um manual com normas de tratamento a ser dado por todas as disciplinas citadas pela Lei $\mathrm{n}^{\circ} 10.639$, amarrando nessa publicação os elementos considerados mais difusos nos PCNs.

\title{
Africa, Brazil and changes in ENEM: the Law n. 10.639/2003
}

\begin{abstract}
This article focuses and tries to analyze the impact of Law 10.369/2003 in the formulation of questions of the High School's National Exam (ENEM) in the period between 1998 and 2015. Thus, the research is situated at the confluence of two public policy initiatives of great relevance in contemporary Brazil: first, of generalist nature and related to the evaluation process of school education and to the access of students to higher education; and the second, dedicated to the recognition of the contribution of black Africans and their Brazilian descendants to the history and national culture of Brazil.
\end{abstract}

Keywords: School education. Public policy.Law n. 10639/2003. High School'sNationalExam.

\section{África, Brasil y loscambios em ENEM: la Ley $n^{\circ}$ 10.639/2003}

\section{Resumen}

Este artículo se centra y analiza el impacto de la Ley 10.639/2003 en temas de formulación del Examen Nacional de Educación Secundaria (ENEM) eN el periodo entre 1998 y 2015. Por lo tanto, la investigación se encuentra eN la confluencia de dos iniciativas políticas públicas de gran relevancia en el Brasil contemporáneo: la primera, de carácter general y que dice sobre el proceso de evaluación de la enseñanza escolar y los estudiantes del acceso a la educación superior; y la segunda ,para el reconocimiento de la contribución de los africanos y sus descendientes para la historia de Brasil y la cultura nacional.

Palabras clave: Educación escolar. Políticas públicas. Ley $n^{\circ}$ 10.639/2003. Examen Nacional de Educación Secundaria. 


\section{Referências}

BARROS, A. Vestibular e Enem: um debate contemporâneo.Ensaio: Avaliação e Políticas Públicas em Educação, v. 22, n. 85, p. 1057-90, out. 2014. https://doi.org/10.1590/S0104-40362014000400009

BATISTA, A.; SILVA JUNIOR, P.; CANEN, A. Em busca de um diálogo entre Plano Nacional de Educação (PNE), formação de professores e multi/interculturalismo. Ensaio: Avaliação e Políticas Públicas em Educação, v. 21, n. 79, p. 253-67, abr./jun. 2013.

BORGES, J. A criança negra: identidade étnica e socialização. Cadernos de Pesquisa, n. 63, p. 41-5, 1982.

BRASIL. Lei No 4.024, de 20 de dezembro de 1961. Fixa as Diretrizes e Bases da Educação Nacional. Diário Oficial da União, 27 dez. 1961.

BRASIL. Lei $\mathrm{N}^{\mathrm{o}} 7.716$, de 5 de janeiro de 1989. Define os crimes resultantes de preconceito de raça ou de cor. Diário Oficial da União, 6 jan. 1989.

. Lei $\mathrm{N}^{\circ} 10.639$, de 9 de janeiro de 2003a. Altera a Lei ${ }^{\circ} 9.394$, de 20 de dezembro de 1996, que estabelece as diretrizes e bases da educação nacional, para incluir no currículo oficial da Rede de Ensino a obrigatoriedade da temática "História e Cultura Afro-Brasileira", e dá outras providências. Diário Oficial da União, 10 jan. 2003a.

CANEN, A.; XAVIER, G. P. M. Multiculturalismo, pesquisa e formação de professores: o caso das Diretrizes Curriculares para a Formação Docente. Ensaio: Avaliação e Políticas Públicas em Educação, v.13, n. 48, p. 333-344, jul./set. 2005. https://doi.org/10.1590/S0104-40362005000300004

COSTA, C. Democracia racial e educação: uma complexa relação. In: MÜLLER, M.; PAIXÃO, L. Olhares sobre a educação: pesquisando raça, classe social, gênero e geração. Cuiabá, MT: EdUFMT, 2013. p. 115-26.

DIAS, L. Quantos passos já foram dados? A questão da raça nas leis educacionais - da LDB de 1961 à Lei 10.639, de 2003. In: ROMÃO, J. (org.). História da educação do negro e outras histórias. Brasília, DF: Ministério da Educação, 2005. p. 49-62.

FREYRE, G. Casa grande e senzala. 51. ed. Rio de Janeiro: Globo, 2006.

GUIMARÃES, A. Classes, raças e democracia. São Paulo: Ed. 34, 2002. 
MOREIRA, M. A. Análise do impacto da Lei 10.630/2003 no Exame Nacional do Ensino Médio entre 1998 e 2013. 2015. 98p. Dissertação (Mestrado em Relações Étnico-Raciais) -Centro Federal de Educação Tecnológica Celso Suckow da Fonseca - CEFET, Rio de Janeiro, 2015.

ORTIZ, R. Universalismo e diversidade. São Paulo: Boitempo, 2015.

PEREIRA, A. Escola: um espaço privilegiado para a construção da cultura de consciência negra. In: ROMÃO, J. (org.). História da educação do negro e outras histórias. Brasília, DF: Ministério da Educação, 2005. p. 35-48.

SAVIANI, D. A nova lei de educação: trajetória, limites e perspectivas. 5. ed., Campinas: Autores Associados, 1999.

\section{Informações dos autores}

Alvaro de Oliveira Senra: Doutor em Ciências Sociais pela UERJ. Professor do mestrado do Programa de Pós-Graduação em Relações Étnico-Raciais e da Coordenação de História do Centro Federal de Educação Tecnológica Celso Suckow da Fonseca (Cefet-RJ). Contato: alvarosenra@gmail.coom

Márcio de Araújo Moreira: Professor do Centro Federal de Educação Tecnológica Celso Suckow da Fonseca (Cefet-RJ). Coordenador do Colegiado de Geografia. Mestre em Relações Étnico-Raciais pelo Cefet-RJ. Contato: maraujom@hotmail.com

Celiana Maria dos Santos: Pedagoga do Instituto Federal de Educação, Ciência e Tecnologia da Bahia (IFBA). Professora da rede Estadual de Educação da Bahia (SEC/BA). Mestre em Relações Étnico-Raciais pelo Centro Federal de Educação Tecnológica Celso Suckow da Fonseca (Cefet-RJ).Contato: celiana@ifba.edu.br 